\title{
Markers of potassium homeostasis in salt losing tubulopathies- associations with hyperaldosteronism and hypomagnesemia
}

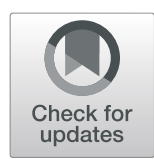

Michael Eder ${ }^{1}$, Elisabeth Darmann ${ }^{1}$, Maria C. Haller ${ }^{2}$, Marija Bojic ${ }^{1}$, Markus Peck-Radosavljevic ${ }^{3}$, Rainer Huditz ${ }^{3}$, Gregor Bond ${ }^{1}$, Andreas Vychytil ${ }^{1}$, Roman Reindl-Schwaighofer ${ }^{1}$ and Željko Kikić ${ }^{*}$ (D)

\begin{abstract}
Background: Renal loss of potassium $\left(\mathrm{K}^{+}\right)$and magnesium $\left(\mathrm{Mg}^{2+}\right)$ in salt losing tubulopathies (SLT) leads to significantly reduced Quality of Life (QoL) and higher risks of cardiac arrhythmia. The normalization of $\mathrm{K}^{+}$is currently the most widely accepted treatment target, however in even excellently designed RCTs the increase of $\mathrm{K}^{+}$was only mild and rarely normalized. These findings question the role of $\mathrm{K}^{+}$as the ideal marker of potassium homeostasis in SLT. Aim of this hypothesis-generating study was to define surrogate endpoints for future treatment trials in SLT in terms of their usefulness to determine QoL and important clinical outcomes.

Methods: Within this prospective cross-sectional study including 11 patients with SLTs we assessed the biochemical, clinical and cardiological parameters and their relationship with QoL (RAND SF-36). The primary hypothesis was that QoL would be more dependent of higher aldosterone concentration, assessed by the transtubular-potassium-gradient (TTKG). Correlations were evaluated using Pearson's correlation coefficient.

Results: Included patients were mainly female (82\%, mean age $34 \pm 12$ years). Serum $\mathrm{K}^{+}$and $\mathrm{Mg}^{2+}$ was $3.3 \pm 0.6$ $\mathrm{mmol} / \mathrm{l}$ and $0.7 \pm 0.1 \mathrm{mmol} / \mathrm{l}$ (mean $\pm \mathrm{SD}$ ). TTKG was 9.5/3.4-20.2 (median/range). While dimensions of mental health mostly correlated with serum $\mathrm{Mg}^{2+}(r=0.68, p=0.04)$ and $\mathrm{K}^{+}(r=0.55, p=0.08)$, better physical health was associated with lower aldosterone levels $(r=-0.61, p=0.06)$. TTKG was neither associated with aldosterone levels nor with QoL parameters. No relevant abnormalities were observed in neither $24 \mathrm{~h}$-ECG nor echocardiography.

Conclusions: Hyperaldosteronism, $\mathrm{K}^{+}$and $\mathrm{Mg}^{2+}$ were the most important parameters of QoL. TTKG was no suitable marker for hyperaldosteronism or QoL. Future confirmatory studies in SLT should assess QoL as well as aldosterone, $\mathrm{K}^{+}$and $\mathrm{Mg}^{2+}$.
\end{abstract}

Keywords: Gitelman syndrome, Bartter syndrome, Transtubular potassium gradient, TTKG, Quality of life

\section{Background}

Salt losing tubulopathies (SLT), most prominently Gitelman (GS) and Bartter-Syndrome (BS) represent the most frequent genetic tubular disorders [1]. BS includes different types of autosomal-recessive inherited disorders

\footnotetext{
* Correspondence: zeljko.kikic@meduniwien.ac.at

${ }^{1}$ Division of Nephrology and Dialysis, Department of Medicine III, Medical University Vienna, Währinger Gürtel 18-20, A-1090 Vienna, Austria Full list of author information is available at the end of the article
}

(Type I-V) resulting in severely reduced electrolyte reabsorption by the thick ascending limb of Henle while GS is caused by mutations in the thiazide sensitive sodium chloride co-transporter (NCCT) gene [2]. Typical clinical findings include renal loss of potassium $\left(\mathrm{K}^{+}\right)$, magnesium $\left(\mathrm{Mg}^{2+}\right)$ and calcium $\left(\mathrm{Ca}^{2+}\right)$, leading to hypokalemia and metabolic alkalosis as well as increased renin and aldosterone levels.

C C The Author(s). 2020 Open Access This article is licensed under a Creative Commons Attribution 4.0 International License, which permits use, sharing, adaptation, distribution and reproduction in any medium or format, as long as you give appropriate credit to the original author(s) and the source, provide a link to the Creative Commons licence, and indicate if changes were made. The images or other third party material in this article are included in the article's Creative Commons licence, unless indicated otherwise in a credit line to the material. If material is not included in the article's Creative Commons licence and your intended use is not permitted by statutory regulation or exceeds the permitted use, you will need to obtain permission directly from the copyright holder. To view a copy of this licence, visit http://creativecommons.org/licenses/by/4.0/ The Creative Commons Public Domain Dedication waiver (http://creativecommons.org/publicdomain/zero/1.0/) applies to the data made available in this article, unless otherwise stated in a credit line to the data. 
Although earlier reports described patients with GS as mostly asymptomatic at presentation, Cruz et al. showed that in some patients quality of life (QoL) was markedly affected and comparable to other chronic diseases usually considered more severe such as diabetes mellitus or congestive heart failure [3-6]. Since SLTs originate from genetic mutations and causal therapies are not available yet, the therapy rather focuses on alleviation of symptoms via electrolyte supplementation. However, little is known about the relationship of biochemical parameters with QoL parameters.

The normalization of serum-potassium levels is currently the most widely accepted treatment target and therefore used as primary endpoint in clinical trials [7]. However, in even excellently designed randomized crossover trials, the increase of potassium with various treatment regimens was only mild and rarely within normal range [7]. Moreover, potassium correction may remain refractory due to underlying magnesium deficiency [8]. These findings question the role of serum $\mathrm{K}^{+}$as the ideal marker of potassium homeostasis in SLT since simultaneous $\mathrm{Mg}^{2+}$ and $\mathrm{Ca}^{2+}$ wasting may also impact QoL. These electrolyte disbalances are further known to increase the risk for cardiac events in SLTs and in the general population [9]. Moreover, palpitations are a frequent symptom in SLTs which may per se affect QoL [6]. Therefore, additional thorough cardiac evaluation is essential not only to diagnose clinically inapparent cardiac abnormalities but also to exclude cardiac disease as a cause of reduced QoL.

The aim of this prospective cross-sectional hypothesisgenerating study was to define surrogate endpoints for future treatment trials in SLT in terms of their usefulness to determine QoL and important clinical outcomes.

Our primary hypothesis was that higher aldosterone levels are associated with a poorer QoL and at the same time an increased risk for cardiac arrhythmias. As the measurement of aldosterone is costly, timedevouring and impracticable in daily routine, we additionally assessed the transtubular potassium gradient (TTKG) which was previously reported as a surrogate of aldosterone activity [10]. The TTKG is considered to quantify the renal potassium secretion by the cortical collecting duct, corrected for water reabsorption and was used as a parameter for guided diuretic treatment in other conditions with increased RAAS activity such as liver cirrhosis [11-13].

\section{Methods}

\section{Study design}

This is a prospectively designed cross-sectional hypothesis-generating study which was carried out in two different tertiary clinical centers in Austria (Medical University of Vienna and Klinikum Klagenfurt) after approval of the associated ethics committees (EK NR 1649/2017 and A 01/18). Medical files were screened for individuals with genetically or clinically diagnosed Bartter- or Gitelman-Syndrome. Patients entered the study after written informed consent assuring adherence to the declarations of Helsinki and Istanbul.

\section{Basic laboratory- and clinical findings}

Basic demographic- and clinical findings were collected from electronic- and paper-based patient files. Intake of relevant medication (electrolyte supplements, diuretics) was recorded. Venous blood samples were collected for measurements of complete blood counts as well as blood chemistry including sodium, potassium, chloride, calcium, magnesium, albumin, creatinine, urea, uric acid, TSH and serum osmolarity. Urine electrolytes and urinary levels of urea, uric acid, creatinine, total protein, micro albumin and urine-osmolarity were measured from spot urine samples. TTKG was calculated according to the ratio of potassium in urine to serum adjusted for water reabsorption (ratio urine/plasma osmolarity).

\section{Study aim}

The primary hypothesis was that higher plasma aldosterone concentrations and the additionally assessed TTKG were related to worse quality of life and higher risk for cardiac events and therefore better surrogate endpoints for treatment trials compared to serum potassium levels alone. Our secondary hypothesis was that other electrolyte disturbances frequently observed in SLTs, particularly magnesium and calcium levels were also related to QoL and cardiac abnormalities.

\section{Quality of life}

RAND SF-36, a standardized questionnaire compound of 36 questions evaluating quality of life, was assessed in all patients [14]. The questionnaire consists of eight subdomains which are physical functioning, role limitations due to physical health, role limitations due to emotional problems, energy/fatigue, emotional well-being, socialfunctioning, pain and general health. We evaluated the RAND SF-36 questionnaire following the manufacturer instructions [14, 15]. We analyzed each quality of life subdomain separately. The score of each domain ranges from 0 to 100, with higher scores representing higher QoL. Physical quality of life and emotional quality of life were summarized to the physical (PCS) - and mental component scores (MCS). Summary scores were constructed by $\mathrm{z}$-transformation and multiplication with corresponding coefficients of each domain. Coefficients for each domain are assumed to be country specific. The coefficients used in this evaluation are based on the general German population and were obtained from the cited source [16]. 


\section{Cardiological evaluation}

Every patient was examined by transthoracic echocardiogram (TTE), and a 24-h electrocardiography. The following parameters were recorded: left atrial dimension, left ventricular dimension and mass, interventricular septum diameter, ejection fraction, longitudinal strain and the presence of wall movement disorder. The 24-h ECG was evaluated for basic rhythm, heart rate (minimum, maximum and mean), occurrence of arrhythmias and extrasystoles of ventricular or supraventricular origin. Episodes of tachycardia or bradycardia were noted when a heart rate of $<60 \mathrm{bpm}$ or $>100 \mathrm{bpm}$ occurred. Lowest/highest heart rate within $24 \mathrm{~h}$ as well as longest episode of bradycardia/ tachycardia were documented. Before every 24-h ECG, a 12-lead resting ECG was performed. The corrected QT interval (QTc) was calculated according to the Bazett formula. A QTc of $<440 \mathrm{~ms}$ was considered normal $[17,18]$.

\section{Statistical analysis}

Continuous variables were expressed as mean and standard deviation or median and absolute range, whichever was appropriate depending on the distribution of the data. Categorical variables were expressed as absolute and relative frequencies. Correlations were evaluated using Pearson's correlation coefficient. In a second step, univariate and multivariate linear regression analysis was applied to determine laboratory parameters independently associated with aspects of QoL. Potential confounders of the effect size of the association between MCS/PCS and $\mathrm{Mg}^{2+} /$ aldosterone were assessed using multivariate linear regression. A change in the effect size of $>10 \%$ was defined as significant. For multivariate analysis co-variables were selected on the basis of clinical relevance. According to recent literature a minimum of two subjects per variable are sufficient for interpretation of regression coefficients in multivariable linear regression [19]. Log normally distributed variables were log transformed. $P$-values $<0.05$ were considered statistically significant. Statistical analysis was performed using commercially available software systems (Microsoft Office Excel; Microsoft Corp., Redmond, WA; SPSS; Version 25, SPSS Inc., Chicago, IL).

\section{Results}

\section{Study participants}

Eleven adult patients were screened for eligibility to enter the study, none of them refused participation. All patients were enrolled in the study between October 2017 and October 2018. Baseline characteristics of included patients are described in Table 1 . Nine patients were diagnosed with GS, two with BS. Nine patients had their diagnosis genetically confirmed: seven patients with mutations in the SLC12A3 gene; two patients with mutations in the SLC12A1 gene. The majority of patients was female $(N=$
Table 1 Basic characteristics of the study population. All non-metric parameters are shown as absolute values and by percentages. Continuous variables are expressed as median and range. ${ }^{*}$ : mean \pm standard deviation $(\mathrm{SD}) ;{ }^{+}$median/range; $\mathrm{K}=$ potassium, $\mathrm{Mg}^{2+}=$ magnesium, $\mathrm{Ca}^{2+}=$ calcium, $\mathrm{Na}^{+}=$sodium, TTKG = transtubular potassium gradient, $\mathrm{N}=$ number, $\mathrm{PSD}=$ potassium-sparing diuretic (eplerenone and spironolactone)

\begin{tabular}{|c|c|}
\hline \multicolumn{2}{|l|}{ Basic characteristics } \\
\hline Patients; N/\% & 11 \\
\hline Female; N/\% & $9(81.8)$ \\
\hline Age at diagnosis (years)* & $24.1 \pm 14.0$ \\
\hline Age at study inclusion (years)* & $33.9 \pm 12.4$ \\
\hline Time since diagnosis (years) ${ }^{+}$ & $10(2-26)$ \\
\hline Bartter-Syndrome; N/\% & $2(22)$ \\
\hline Gitelman-Syndrome; N/\% & $9(78)$ \\
\hline Medication; N/\% & $10(91)$ \\
\hline Patients with $\mathrm{K}^{+}$and $\mathrm{Mg}^{2+}$ Supplements; N/\% & $7(70)$ \\
\hline PSD; N/\% & $6(60)$ \\
\hline \multicolumn{2}{|l|}{ Laboratory findings } \\
\hline $\mathrm{K}^{+} \mathrm{mmol} / \mathrm{L}_{i}^{*}$ & $3.3 \pm 0.6$ \\
\hline $\mathrm{Ca}^{2+} \mathrm{mmol} / \mathrm{L}_{i}^{*}$ & $2.5 \pm 0.2$ \\
\hline $\mathrm{Mg}^{2+} \mathrm{mmol} / \mathrm{L}_{i}^{*}(\mathrm{n}=9)$ & $0.7 \pm 0.1$ \\
\hline $\mathrm{Na}^{+} \mathrm{mmol} / \mathrm{Li}_{i}^{+}$ & 139/132.0-142.0 \\
\hline Osmolarity mosm $/ \mathrm{kg}_{i}^{+}$ & $286.0 / 282.0-291.0$ \\
\hline Aldosterone $\mathrm{pg} / \mathrm{ml} ;^{+}(n=10)$ & 259.0.2/76.0-985.0 \\
\hline \multicolumn{2}{|l|}{ Urinary laboratory findings } \\
\hline $\mathrm{K}^{+} \mathrm{mmol} / \mathrm{Li}_{i}^{+}$ & $33.0 / 9.0-120.0$ \\
\hline $\mathrm{Na}^{+} \mathrm{mmol} / \mathrm{Li}_{i}^{+}$ & $62.0 / 17.0-142.0$ \\
\hline Osmolarity mosm $/ \mathrm{kg}_{i}^{+}$ & 294.0/101.0-830 \\
\hline TTKG:+ & $9.5 / 3.4-20.2$ \\
\hline
\end{tabular}

9 [81.8\%]), mean age at study inclusion was $33.9 \pm 12.4$ years (mean $\pm \mathrm{SD}$ ). The median time since initial diagnosis was 10.0/2.0-26.0 years (median/range).

\section{Routine treatment protocol}

All patients were instructed to keep a diet rich in sodium, potassium and magnesium. Further, seven patients took $\mathrm{K}^{+}$and $\mathrm{Mg}^{2+}$ supplements and potassium-sparing diuretics (PSD) were used in six patients (spironolactone $[N=4]$, amiloride $[N=1]$ eplerenone $[\mathrm{N}=1]$, see Table 1). The median supplement based daily potassium- and magnesium intake was $64 / 0-304 \mathrm{mmol} / \mathrm{d}$ (median/range) and $7.5 / 0-30 \mathrm{mmol} / \mathrm{d}$ (median/range) respectively. Based on the clinic protocols, all patients were invited to ambulatory follow-ups every three months or upon clinical symptoms. The median number of ambulatory visits/blood collections at the center within the last year before study inclusion was 3/1-12 (median/range) respectively. 


\section{Laboratory findings}

Patients presented with mild hypokalemia $(3.3 \pm 0.6$ $\mathrm{mmol} / \mathrm{L}[$ mean $\pm \mathrm{SD}])$ and hypomagnesemia $(0.7 \pm 0.1$ $\mathrm{mmol} / \mathrm{L})$. Serum osmolarity as well as sodium- and calcium levels were within the normal range (286.0/282.0$291.0 \mathrm{mosm} / \mathrm{kg}$ [median/range]; $139 / 132.0-142.0 \mathrm{mmol} /$ $\mathrm{L} ; 2.5 \pm 0.2 \mathrm{mmol} / \mathrm{L}$ ). The median aldosterone level was 259.0/76.0-985.0 pg/ml. Median urinary $\mathrm{Na}^{+}$and $\mathrm{K}^{+}$ levels were $62.0 / 17.0-142.0 \mathrm{mmol} / \mathrm{L}$ (median/range) and 33.0/9.0-120.0 $\mathrm{mmol} / \mathrm{L}$ (median/range) respectively. The median TTKG was 9.5/3.4-20.2 (median/range).

\section{TTKG is not associated with plasma aldosterone}

\section{concentration}

Of note, we could not document a correlation of serum potassium - $(\mathrm{r}=0.43, p=0.22)$ or TTKG $(\mathrm{r}=-0.21, p=$ 0.56) with aldosterone (Fig. 1a). Likewise, using TTKG as a dichotomous variable according to the median of 10 $(\mathrm{r}=0.06)$ as well as excluding cases with lower urine osmolality $(n=4)$, TTKG did not correlate with plasma aldosterone levels. TTKG was only associated with urinary potassium levels $(r=0.52)$. We further performed a sub analysis according to the use of potassium sparing diuretics (PSD). The correlation coefficient for TTKG with plasma aldosterone was $-0.12(p=0.86)$ in the PSD group compared to $-0.09(p=0.89)$ in the group without potassium sparing diuretics. Moreover, as shown in Table 2 we did not observe statistically significant differences in TTKGs, plasma- or urinary potassium levels and aldosterone levels in subjects with or without PSD.

\section{Quality of life}

QoL scores of all eight domains are shown in Table 3. Higher scores in each subdomain represent better QoL parameters. Lowest scores were found in the categories role limitations due to physical health and fatigue
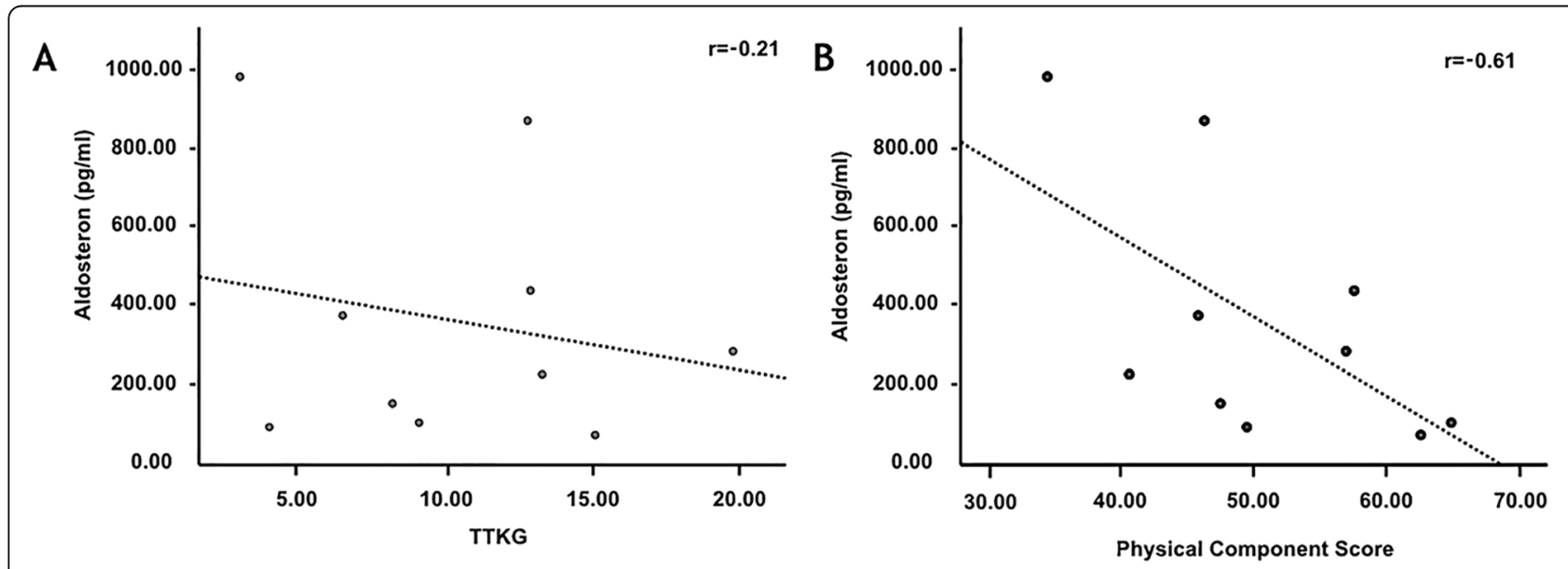

C

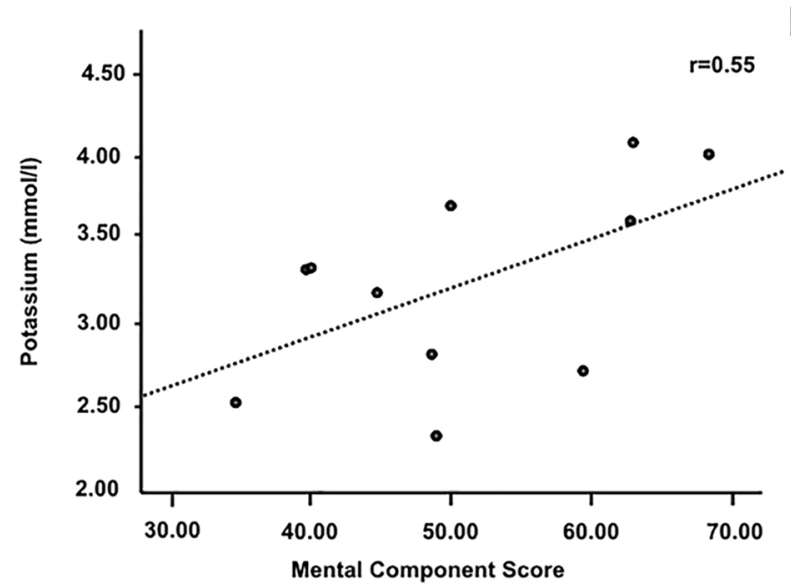

D

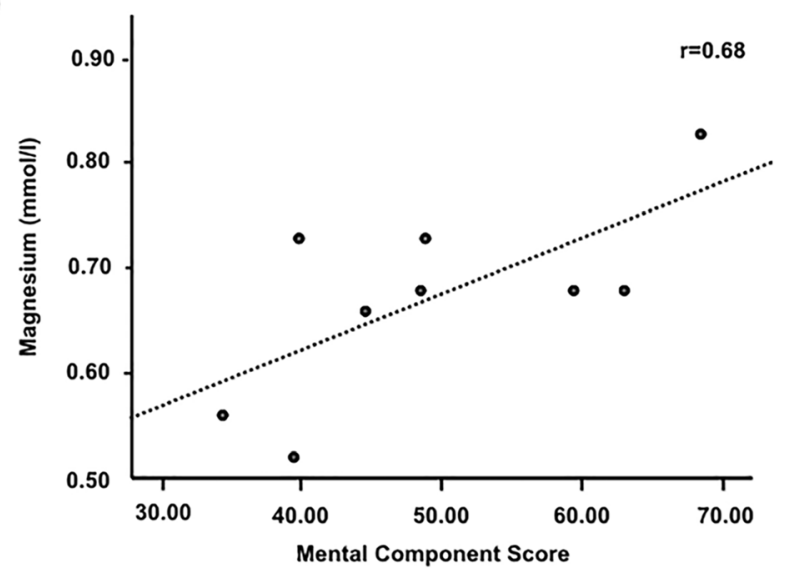

Fig. 1 a-d Major correlations of biochemical findings and domains of QoL: a) The transtubular potassium gradient (TTKG) is not associated with plasma aldosterone levels. b) We found a trend towards higher plasma aldosterone levels and reduced Quality of Life domains of physical health, assessed by the physical component score. c) Higher serum potassium levels showed a trend towards increase of Quality of Life domains of mental health, assessed by the mental component score. $\mathbf{d}$ ) Higher serum $\mathrm{Mg}^{2+}$ levels are significantly associated with an increase of Quality of Life domains of mental health, assessed by the mental component score 
Table 2 Plasma aldosterone, potassium and TTKG between patients with and without potassium sparing diuretics

\begin{tabular}{|c|c|c|c|c|}
\hline & All & Patients with PSD & Patients without PSD & $p$ \\
\hline Patients; N/\% & 11 & $6(54.5)$ & $5(45.5)$ & \\
\hline Plasma $\mathrm{K}^{+} \mathrm{mmol} / \mathrm{L}_{i}^{*}$ & $3.3 \pm 0.6$ & $3.5 \pm 0.6$ & $2.9 \pm 0.9$ & 0.126 \\
\hline Urinary $\mathrm{K}^{+} \mathrm{mmol} / \mathrm{L}_{i}^{+}$ & $33 / 9-120$ & $54 / 13-120$ & $33 / 9-63$ & 0.537 \\
\hline Aldosterone $\mathrm{pg} / \mathrm{ml} ;^{+}(\mathrm{n}=10)$ & $259 / 76-985$ & $442 / 96-985$ & 156/76-379 & 0.222 \\
\hline $\mathrm{TTKG}_{i}^{+}$ & $9.5 / 3.4-20.2$ & $9.4 / 3.4-13.7$ & $9.5 / 6.9-20.2$ & 0.329 \\
\hline
\end{tabular}

*: mean \pm standard deviation $(\mathrm{SD})^{+}:$median/range; $\mathrm{K}=$ potassium, $T \mathrm{KKG}=$ transtubular potassium gradient, $\mathrm{N}=$ number, $\mathrm{PSD}=$ potassium-sparing diuretic (eplerenone and spironolactone)

Table $3 \mathrm{a}$ and b Correlation of biochemical parameters with the physical component score, mental component score and single domains of Quality of Life: Correlation are calculated using Pearson correlation. Significant findings are highlighted. $\mathrm{K}=$ potassium $\mathrm{Mg}^{2+}=$ magnesium, $\mathrm{Ca}^{2+}=$ calcium, $\mathrm{Na}^{+}=$sodium, $\Pi \mathrm{TK}=$ transtubular potassium gradient, $\mathrm{N}=$ number, $\mathrm{PSD}=$ potassium-sparing diuretic

\begin{tabular}{|c|c|c|c|c|c|c|c|c|c|c|}
\hline & \multicolumn{10}{|c|}{ Domains of physical health } \\
\hline & \multicolumn{2}{|c|}{$\begin{array}{l}\text { Physical } \\
\text { Component Score }\end{array}$} & \multicolumn{2}{|c|}{ Physical Functioning } & \multicolumn{2}{|c|}{$\begin{array}{l}\text { Role limitations- } \\
\text { Physical }\end{array}$} & \multicolumn{2}{|l|}{ Pain } & \multicolumn{2}{|c|}{ General health } \\
\hline & $\mathrm{R}$ & $\overline{p \text {-value }}$ & $\bar{R}$ & $p$-value & $R$ & $\overline{p \text {-value }}$ & $\mathrm{R}$ & $\overline{p \text {-value }}$ & $\bar{R}$ & $\overline{p \text {-value }}$ \\
\hline TTKG $>10$ & 0.28 & 0.39 & 0.40 & 0.22 & -0.20 & 0.57 & 0.04 & 0.91 & 0.28 & 0.39 \\
\hline Plasma $\mathrm{K}^{+}, \mathrm{mmol} / \mathrm{l}$ & -0.28 & 0.41 & -0.22 & 0.52 & -0.23 & 0.49 & 0.17 & 0.62 & 0.54 & 0.09 \\
\hline Plasma $\mathrm{K}^{+}>3 \mathrm{mmol} / \mathrm{l}$ & -0.33 & 0.33 & -0.20 & 0.57 & -0.45 & 0.17 & 0.09 & 0.79 & 0.29 & 0.39 \\
\hline Urinary $\mathrm{K}^{+}, \mathrm{mmol} / \mathrm{l}$ & -0.12 & 0.73 & 0.29 & 0.38 & -0.36 & 0.28 & -0.19 & 0.56 & -0.24 & 0.49 \\
\hline Urinary $\mathrm{K}^{+}>20 \mathrm{mmol} / \mathrm{l}$ & 0.11 & 0.74 & 0.43 & 0.18 & -0.21 & 0.53 & -0.04 & 0.91 & 0.11 & 0.74 \\
\hline Plasma $\mathrm{Mg}^{2+}, \mathrm{mmol} / \mathrm{l}$ & 0.31 & 0.42 & -0.25 & 0.51 & 0.65 & 0.06 & 0.18 & 0.64 & 0.25 & 0.52 \\
\hline Plasma $\mathrm{Ca}^{2+}, \mathrm{mmol} / \mathrm{l}$ & -0.30 & 0.39 & -0.55 & 0.10 & -0.42 & 0.23 & 0.03 & 0.93 & 0.28 & 0.44 \\
\hline Plasma $\mathrm{Na}^{+}, \mathrm{mmol} / \mathrm{l}$ & 0.28 & 0.41 & 0.61 & 0.05 & 0.26 & 0.44 & 0.04 & 0.90 & -0.29 & 0.38 \\
\hline Urinary $\mathrm{Na}^{+}, \mathrm{mmol} / \mathrm{l}$ & -0.35 & 0.32 & -0.03 & 0.93 & -0.30 & 0.41 & -0.35 & 0.32 & -0.52 & 0.13 \\
\hline Urinary $\mathrm{Na}^{+} / \mathrm{K}^{+}$ratio & -0.14 & 0.70 & -0.13 & 0.72 & 0.20 & 0.59 & -0.25 & 0.49 & -0.08 & 0.83 \\
\hline \multirow[t]{4}{*}{ Aldosterone, pg/ml } & -0.61 & 0.06 & -0.50 & 0.14 & -0.74 & 0.02 & 0.17 & 0.62 & -0.54 & 0.09 \\
\hline & \multicolumn{10}{|c|}{ Domains of mental health } \\
\hline & \multicolumn{2}{|c|}{$\begin{array}{l}\text { Mental } \\
\text { Component score }\end{array}$} & \multicolumn{2}{|c|}{$\begin{array}{l}\text { Role limitations- } \\
\text { Mental }\end{array}$} & \multicolumn{2}{|c|}{ Energy/Fatigue } & \multicolumn{2}{|c|}{ Mental health } & \multicolumn{2}{|c|}{ Social functioning } \\
\hline & $\mathrm{R}$ & $p$-value & $\mathrm{R}$ & $p$-value & $\mathrm{R}$ & $p$-value & $\mathrm{R}$ & $p$-value & $\mathrm{R}$ & $\mathrm{p}$-value \\
\hline TTKG $>10$ & -0.41 & 0.21 & -0.01 & 0.97 & -0.39 & 0.23 & -0.23 & 0.49 & -0.30 & 0.37 \\
\hline Plasma $\mathrm{K}^{+}, \mathrm{mmol} / \mathrm{l}$ & 0.55 & 0.08 & -0.02 & 0.95 & 0.56 & 0.07 & 0.70 & 0.01 & 0.28 & 0.39 \\
\hline Plasma K $\mathrm{K}^{+}>3 \mathrm{mmol} / \mathrm{l}$ & 0.22 & 0.52 & -0.27 & 0.42 & 0.33 & 0.32 & 0.45 & 0.17 & -0.05 & 0.89 \\
\hline Urinary $\mathrm{K}^{+}, \mathrm{mmol} / \mathrm{l}$ & -0.47 & 0.14 & -0.08 & 0.81 & -0.48 & 0.14 & -0.28 & 0.39 & -0.42 & 0.19 \\
\hline Urinary $\mathrm{K}^{+}>20 \mathrm{mmol} / \mathrm{l}$ & -0.66 & 0.03 & 0.04 & 0.89 & -0.83 & 0.002 & -0.56 & 0.07 & $-0,34$ & 0.31 \\
\hline Plasma $\mathrm{Mg}^{2+}, \mathrm{mmol} / \mathrm{l}$ & 0.68 & 0.04 & 0.48 & 0.19 & 0.40 & 0.28 & 0.48 & 0.28 & 0.74 & 0.02 \\
\hline Plasma $\mathrm{Ca}^{2+}, \mathrm{mmol} / \mathrm{l}$ & -0.06 & 0.87 & -0.47 & 0.17 & 0.11 & 0.76 & -0.02 & 0.95 & -0.11 & 0.75 \\
\hline Plasma $\mathrm{Na}^{+}, \mathrm{mmol} / \mathrm{l}$ & -0.06 & 0.85 & 0.43 & 0.19 & -0.31 & 0.35 & -0.05 & 0.89 & 0.09 & 0.78 \\
\hline Urinary $\mathrm{Na}^{+}, \mathrm{mmol} / \mathrm{l}$ & -0.37 & 0.29 & 0.09 & 0.81 & -0.55 & 0.10 & -0.39 & 0.26 & -0.13 & 0.73 \\
\hline Urinary $\mathrm{Na}^{+} / \mathrm{K}^{+}$ratio & 0.22 & 0.53 & 0.33 & 0.36 & 0.06 & 0.89 & 0.17 & 0.65 & 0.25 & 0.49 \\
\hline Aldosterone, pg/ml & -0.26 & 0.46 & -0.49 & 0.15 & -0.05 & 0.89 & -0.14 & 0.71 & -0.45 & 0.19 \\
\hline
\end{tabular}


$(38.6 \pm 42.4 \quad[$ mean $\pm \mathrm{SD}] ; \quad 40.9 \pm 29.0 \quad[$ mean $\pm \mathrm{SD}])$, whereas scores of social functioning and role limitations due to emotional problems showed the highest levels $(70.5 \pm 25.2,60.6 \pm 41.7)$. Both composite scores, the physical component score (PCS) as well as the mental component score (MCS) were rated similarly with mean scores of $50.0 \pm 9.5($ mean \pm SD) and $50.0 \pm 10.7$ (mean \pm $\mathrm{SD})$.

\section{Single domains of QoL and laboratory findings}

Table $3 \mathrm{a}$ and $\mathrm{b}$ illustrate the association of biochemical parameters with single and composite domains of QoL. Higher serum $\mathrm{K}^{+}$significantly correlated with emotional well-being $(\mathrm{r}=0.70, p=0.01)$ and showed a trend for better general health $(\mathrm{r}=0.54, p=0.09)$ and less fatigue $(\mathrm{r}=0.56, p=0.07)$. Aldosterone levels and limitations due to physical health (RP) were negatively correlated $(\mathrm{r}=-0.74, p=0.02)$. Serum $\mathrm{Mg}^{2+}$ levels had a significant positive correlation with social functioning $(\mathrm{r}=0.74, \mathrm{p}=$ 0.02). Further, $\mathrm{Mg}^{2+}$ showed a trend towards less limitations due to physical health $(\mathrm{r}=0.65, p=0.06)$. In contrast, neither the TTKG alone nor the TTKG after exclusion of cases with low urine osmolality were significantly correlated with QoL domains. Serum calcium was not related to single domains of QoL. We did not find a significant correlation between QoL domains and the cumulative daily doses of the magnesium- (PCS: $r=-$ $0.10, p=0.77$; MCS: $\mathrm{r}=-0.16, p=0.66)$ and potassium supplementations (PCS: $\mathrm{r}=-0.10, p=0.78$; MCS: $\mathrm{r}=-$ $0.29, p=0.43)$. The same applied for the number of clinic visits/blood samples within the last year (PCS: $\mathrm{r}=$ $-0.35, p=0.29$; MCS: $\mathrm{r}=-0.49, p=0.12$ ).

\section{Component scores of QoL and laboratory findings}

To assess QoL in a more general way we calculated the physical and mental component scores according to standard methodology. As shown in Fig. 1 and Table 3, dimensions of mental health were significantly correlated with $\mathrm{Mg}^{2+}(\mathrm{r}=0.68, p=0.04)$ and showed a trend towards higher serum $\mathrm{K}^{+}$levels $(\mathrm{r}=0.55, p=0.08)$. Further, we found a trend towards better physical health with lower aldosterone levels $(r=-0.61, p=0.06)$. Applying univariate linear regression analysis, the regression coefficient for magnesium and MCS was statistically significant (1.11, [95\% CI: 0.05-2.17]; $p=$ 0.042). Inclusion of TTKG or serum potassium in a multivariate model did not significantly change the regression coefficients. We observed a clinically relevant trend between PCS and aldosterone $(-0.14,[95 \% \mathrm{CI}$, $0.28-0.06], p=0.059)$. Inclusion of serum potassium or TTKG did not significantly change regression coefficients. However, inclusion of aldosterone into the MV model significantly increased the regression coefficient for magnesium and MCS $(1.88, p=0.01)$. These findings support the hypothesis that both magnesium and aldosterone may serve as valuable and synergistic markers of QoL parameters.

\section{Cardiological evaluation}

Cardiological work-up consisted of an echocardiogram and 24-h electrocardiography. The study population showed normal mean left atrial and ventricular dimensions of $33.1 \pm 3.6 \mathrm{~mm}$ and $44.7 \pm 4.3 \mathrm{~mm}$ without signs of hypertrophy (interventricular septum was 8.0/7.0-1.1 $\mathrm{mm}$ [median/range]). Right ventricular dimensions were within normal ranges in all patients. The left ventricular ejection fraction was always above $55 \%$ and the longitudinal strain was normal. We did not find any episodes of arrhythmia with 24-h-electrocardiography. All patients had sinus rhythm with a mean heart rate of $87 \mathrm{bpm}$ (range 53-125). Three patients had sinus tachycardia for more than ten minutes. The median QTc was 425/416$498 \mathrm{~ms}$ (median/range) respectively. Two patients had a prolonged QTc (470 ms and $454 \mathrm{~ms}$ ) and in four patients a U-wave was found.

\section{Discussion}

In comparison to previous reports, this is the first study showing significant correlations of domains of QoL with laboratory findings in SLTs [3, 20]. Higher plasma aldosterone levels correlated significantly with higher limitations due to physical health and showed a trend towards an overall worse physical health perception. Whereas better mental health was significantly correlated with higher serum $\mathrm{Mg}^{2+}$ we also found a trend towards higher serum $\mathrm{K}^{+}$levels. Our findings emphasize that serum potassium alone does not correlate with the overall individual disease burden assessed by QoL instruments and is therefore an insufficient treatment endpoint in randomized controlled trials in SLTs.

Frequent ambulance visits and blood tests, as well as high doses of supplements and the related side effects may be considered a factor contributing to the reduced QoL in SLT patients. However, in our study neither the number of ambulatory tests nor the dose of supplement consumed was correlated with QoL.

The association of $\mathrm{Mg}^{2+}$ with mental health is in line with previous literature reporting efficacy of $\mathrm{Mg}^{2+}$ supplements in relieving anxiety and stress and its use as an analgesic sparing substance in anesthesiology [21, 22]. Moreover, the use of slow-releasing magnesium formulation medications led to an increase of patient reported outcomes in a cohort of GS patients [23].

Since its first description in rat micro puncture studies, TTKG has been considered a reliable surrogate of aldosterone activity [10]. In our study, TTKG did not prove a useful parameter of QoL. Moreover TTKG was not associated with plasma aldosterone concentrations, 
even after exclusion of patients treated with potassium sparing diuretics in a subgroup-analysis. This is in line with a prior study assessing TTKG in drug-induced hyperkalemia which found that TTKG values did not differ between patients with potassium sparing drugs and patients with hyperkalemia of other causes [24]. More recent publications have also questioned the ability of TTKG to reflect aldosterone activity. For instance, Kawada et al. did not detect an association of TTKG with aldosterone in hypertensive patients [25]. Kamel et al. provided a possible explanation for these findings as urea recycling in the medullary collecting duct leads also to a significant amount of potassium wasting and TTKG may therefore rather reflect combined aldosterone and vasopressin activity [26]. The authors, who were also part of the team first describing the TTKG assume that the micropuncture related interruption of urea recycling may explain the discrepancies between the in vivo data and emerging clinical findings [26]. However, a partial effect or a combination of concomitant volume depletion leading to decreased sodium delivery to the collecting duct and an impaired function of the $\mathrm{ENaC}$ may contribute to discrepant results regarding TTKG and aldosterone in some of the studies. From a pathophysiologic perspective, decreased sodium delivery to the $\mathrm{ENaC}$ is an unlikely confounder in salt-losing tubulopathies. Also, in our study we observed only two patients with a urinary sodium level $<25 \mathrm{mmol} / \mathrm{l}$, both without concomitant PSD. We can therefore exclude a relevant effect of decreased sodium delivery to the $\mathrm{ENaC}$ in the overall cohort, which may have partially explained the lack of an association between TTKG and aldosterone in some of the before mentioned studies.

Previous case reports described a high risk for cardiac events including aborted sudden cardiac death events in SLT [9]. Suggested potential mechanisms besides hypokalemia include exercise induced left ventricular dysfunction leading to reduced cardiac index as well as paradoxical QTc prolongation and subsequent cardiac dysfunction during nocturnal vagal stimulation [9]. In our study non-invasive cardiological diagnostics showed prolonged QTc intervals in two patients and $U$ waves in four patients but no evidence for cardiac ventricular dysfunction or prolonged arrhythmia. Therefore, we can safely exclude any impact of clinically inapparent cardiac abnormalities on QoL. However, it should be noted that these patients had only moderate hypokalemia and hypomagnesemia and that our study protocol did not include stress-induced cardiac evaluation. Our results may therefore not be comparable to the beforementioned study.

Some limitations must be considered when interpreting our study. First, there are inherent limitations related to studies in orphan diseases. Due to the low prevalence of SLTs, prospective investigations are difficult to perform. This trial was therefore designed as a hypothesisgenerating study needing testing in a confirmatory study and in this comparably small cohort, significant associations of laboratory parameters and QoL domains were found. We have also corrected our findings with multivariate linear regression models, which provide stable regression coefficients even in smaller sample sizes [19]. However, it must be pointed out, that while the obtained results may provide a valuable basis for future trials they cannot be interpreted as confirmatory and a validation in a larger data set is necessary. Second, the crosssectional study design does not allow a causative interpretation of our findings. Third, our study cohort consists of both BS and GS patients, which may seem heterogeneous from a pathophysiological perspective. The aim of the current study is not the underlying pathophysiology but the clinical phenotype and its QoL related features with distinct focus on the omnipresent role of hyperaldosteronism in SLTs. Moreover, there is broad evidence and consensus that despite the differences expected to be present in tubular electrolyte handling in those syndromes, clinical phenotypes are often undistinguishable with up to $30 \%$ of BS patients having a GS phenotype [1, 27-29]. Further, various conditions present in SLTs can lead to an increase and/or decrease of plasma aldosterone and plasma aldosterone is therefore not a specific marker of potassium depletion [30]. While the current study is not designed to define treatment thresholds for plasma aldosterone concentration it provides evidence that a composite laboratory endpoint of potassium, magnesium and aldosterone concentration may be reflecting QoL more accurately than serum potassium alone.

\section{Conclusions}

To conclude, this is the first study reporting significant associations of biochemical parameters and QoL in patients with SLTs and provides a valuable basis for novel treatment goals and future trials. Confirming our primary hypothesis, mental health was mostly associated with higher $\mathrm{Mg}^{2+}$ levels and trends towards better physical aspects of QoL in patients with lower plasma aldosterone were found.

Future treatment trials in SLT should therefore aim at increasing domains of QoL by influencing serum levels of magnesium, potassium and aldosterone.

\footnotetext{
Abbreviations

BPM: Beats per minute; BS: Bartter-Syndrome; $\mathrm{Ca}^{2+}$ : Calcium; E: Energy/

Fatigue; GH: General health; GS: Gitelman-Syndrome; K+: Potassium;

MCS: Mental component score; $\mathrm{Mg}^{2+}$ : Magnesium; Ms.: Milliseconds;

$\mathrm{Na}^{+}$: Sodium; PCS: Physical component score; PF: Physical functioning; PSD: Potassium-sparing diuretic; QoL: Quality of Life; RAAS: Renin-

Angiotensin-Aldosterone System; RP: Role limitations due to physical
} 
problems; RE: Role limitations due to emotional problems; SF: Social functioning; TTKG: Transtubular potassium gradient

\section{Acknowledgments \\ Not applicable.}

\section{Availability of data}

The datasets generated/and or analyzed during this study are available from the corresponding author on reasonable request.

\section{Authors' contributions}

$\mathrm{ZK}, \mathrm{ED}$ and $\mathrm{MH}$ conceived the study, all authors participated in study design. $M E, Z K, E D, M P R, R H, M B, A V$ and RRS acquired data, ME, ED, MH, GB and ZK contributed to statistical analysis and interpretation. ME and ZK drafted the manuscript, and all authors contributed to manuscript revision and approved the final version.

\section{Funding}

Not applicable.

\section{Ethics approval and consent to participate}

Obtained from Medical University of Vienna and Klinikum Klagenfurt from the associated ethics committees (EK NR 1649/2017 and A 01/18). Written informed consent was obtained from all participants before entering the study.

\section{Consent for publication}

Not applicable.

\section{Competing interests}

The authors declare that they have no competing interests.

\section{Author details}

'Division of Nephrology and Dialysis, Department of Medicine III, Medical University Vienna, Währinger Gürtel 18-20, A-1090 Vienna, Austria. ${ }^{2}$ Institute of Biometrics, Center for Medical Statistics, Informatics, and Intelligent Systems, Medical University of Vienna, Vienna, Austria. ${ }^{3}$ Department of Internal Medicine and Gastroenterology (IMUG), Hepatology, Endocrinology, Rheumatology, Nephrology and Emergency Medicine (ZAE), Klinikum Klagenfurt am Wörthersee, Klagenfurt, Austria.

Received: 21 August 2019 Accepted: 24 June 2020

Published online: 06 July 2020

\section{References}

1. Blanchard A, Bockenhauer D, Bolignano D, et al. Gitelman syndrome: consensus and guidance from a kidney disease: improving global outcomes (KDIGO) controversies conference. Kidney Int. 2017;91(1):24-33.

2. Graziani G, Fedeli C, Moroni L, Cosmai L, Badalamenti S, Ponticelli C. Gitelman syndrome: pathophysiological and clinical aspects. QJM. 2010; 103(10):741-8

3. Monnens L, Bindels R, Grunfeld JP. Gitelman syndrome comes of age Nephrology, dialysis, transplantation : official publication of the European Dialysis and Transplant Association - European Renal Association. 1998;13(7): 1617-9

4. Puschett JB, Greenberg A, Mitro R, Piraino B, Wallia R. Variant of Bartter's syndrome with a distal tubular rather than loop of Henle defect. Nephron. 1988:50(3):205-11.

5. Barbour GL, Day JO. Asymptomatic Bartter's syndrome. South Med J. 1978; 71(11):1341 -1344, 1349

6. Cruz DN, Shaer AJ, Bia MJ, et al. Gitelman's syndrome revisited: an evaluation of symptoms and health-related quality of life. Kidney Int. 2001; 59(2):710-7.

7. Blanchard A, Vargas-Poussou R, Vallet $M$, et al. Indomethacin, amiloride, or eplerenone for treating hypokalemia in Gitelman syndrome. J Am Soc Nephrol. 2015;26(2):468-75

8. Huang $\mathrm{CL}$, Kuo E. Mechanism of hypokalemia in magnesium deficiency. J Am Soc Nephrol. 2007;18(10):2649-52.

9. Scognamiglio R, Negut C, Calo LA. Aborted sudden cardiac death in two patients with Bartter's/Gitelman's syndromes. Clin Nephrol. 2007;67(3):193-7.
10. Ethier JH, Kamel KS, Magner PO, Lemann J Jr, Halperin ML. The transtubular potassium concentration in patients with hypokalemia and hyperkalemia. Am J Kidney Dis. 1990;15(4):309-15.

11. West ML, Marsden PA, Richardson RM, Zettle RM, Halperin ML. New clinical approach to evaluate disorders of potassium excretion. Miner Electrolyte Metab. 1986:12(4):234-8

12. Choi MJ, Ziyadeh FN. The utility of the transtubular potassium gradient in the evaluation of hyperkalemia. J Am Soc Nephrol. 2008;19(3):424-6.

13. Lim YS, Han JS, Kim KA, Yoon JH, Kim CY, Lee HS. Monitoring of transtubular potassium gradient in the diuretic management of patients with cirrhosis and ascites. Liver. 2002;22(5):426-32.

14. Hays RD, Sherbourne CD, Mazel RM. The RAND 36-item health survey 1.0. Health Econ 1993;2(3):217-227.

15. Brazier JE, Harper R, Jones NM, et al. Validating the SF-36 health survey questionnaire: new outcome measure for primary care. BMJ. 1992;305(6846): $160-4$.

16. Ellert U, Kurth B-M. Methodische Betrachtungen zu den Summenscores des SF-36 anhand der erwachsenen bundesdeutschen Bevölkerung. Robert Koch-Institut, Epidemiologie und Gesundheitsberichterstattung: In; 2004

17. Bettinelli A, Tosetto C, Colussi G, Tommasini G, Edefonti A, Bianchetti MG Electrocardiogram with prolonged QT interval in Gitelman disease. Kidney Int. 2002:62(2):580-4.

18. Foglia PE, Bettinelli A, Tosetto C, et al. Cardiac work up in primary renal hypokalaemia-hypomagnesaemia (Gitelman syndrome). Nephrology, dialysis, transplantation : official publication of the European Dialysis and Transplant Association - European Renal Association. 2004;19(6):1398-402.

19. Austin PC, Steyerberg EW. The number of subjects per variable required in linear regression analyses. J Clin Epidemiol. 2015;68(6):627-36.

20. Caiata-Zufferey M, Zanini CA, Schulz PJ, Syren ML, Bianchetti MG, Bettinelli A. Living with Gitelman disease: an insight into patients' daily experiences. Nephrology, dialysis, transplantation : official publication of the European Dialysis and Transplant Association - European Renal Association. 2012;27(8): 3196-201.

21. Do SH. Magnesium: a versatile drug for anesthesiologists. Korean J Anesthesiol. 2013;65(1):4-8.

22. Boyle NB, Lawton C, Dye L. The Effects of Magnesium Supplementation on Subjective Anxiety and Stress-A Systematic Review. Nutrients. 2017;9(5).

23. Robinson CM, Karet Frankl FE. Magnesium lactate in the treatment of Gitelman syndrome: patient-reported outcomes. Nephrology, dialysis, transplantation : official publication of the European Dialysis and Transplant Association - European Renal Association. 2017;32(3):508-12.

24. Mayan H, Kantor R, Farfel Z. Trans-tubular potassium gradient in patients with drug-induced hyperkalemia. Nephron. 2001;89(1):56-61.

25. Kawada N, Isaka Y, Kitamura H, Rakugi H, Moriyama T. A pilot study of the effects of eplerenone add-on therapy in patients taking renin-angiotensin system blockers. J Renin-Angiotensin-Aldosterone Syst. 2015:16(2):360-5.

26. Kamel KS, Halperin ML. Intrarenal urea recycling leads to a higher rate of renal excretion of potassium: an hypothesis with clinical implications. Curr Opin Nephrol Hypertens. 2011;20(5):547-54

27. Seys $E$, Andrini $O$, Keck $M$, et al. Clinical and genetic Spectrum of Bartter syndrome type 3. J Am Soc Nephrol. 2017;28(8):2540-52.

28. Jeck N, Konrad M, Peters M, Weber S, Bonzel KE, Seyberth HW. Mutations in the chloride channel gene, CLCNKB, leading to a mixed Bartter-Gitelman phenotype. Pediatr Res. 2000;48(6):754-8.

29. Garcia Castano A, Perez de Nanclares G, Madariaga L, et al. Poor phenotypegenotype association in a large series of patients with Type III Bartter syndrome. PLoS One. 2017;12(3):e0173581.

30. Xu N, Hirohama D, Ishizawa K, et al. Hypokalemia and Pendrin induction by aldosterone. Hypertension. 2017;69(5):855-62.

\section{Publisher's Note}

Springer Nature remains neutral with regard to jurisdictional claims in published maps and institutional affiliations. 